\title{
Do men regret prostate biopsy: Results from the PiCTure study
}

\author{
Catherine Coyle ${ }^{1 *}$, Eileen Morgan², Frances J. Drummond ${ }^{3,4}$, Linda Sharp ${ }^{3,5+}$ and Anna Gavin ${ }^{2 \dagger}$
}

\begin{abstract}
Background: Understanding men's experience of prostate biopsy is important as the procedure is common, invasive and carries potential risks. The psychological aspects of prostate biopsy have been somewhat neglected. The aim of this study was to explore the level of regret experienced by men after prostate biopsy and identify any associated factors.

Methods: Men attending four clinics in Republic of Ireland and two in Northern Ireland were given a questionnaire to explore their experience of prostate biopsy. Regret was measured on a Likert scale asking men how much they agreed with the statement "It [the biopsy] is something I regret."
\end{abstract}

Results: Three hundred thirty-five men responded to the survey. The mean age was 63 years (SD \pm 7 years). Three quarters of respondents (76\%) were married or co-habiting, and (75\%) finished education at primary or secondary school level. For just over two thirds of men (70\%) their recent biopsy represented their first ever prostate biopsy. Approximately one third of men reported a diagnosis of cancer, one third a negative biopsy result, and the remaining third did not know their result. Two thirds of men reported intermediate or high health anxiety. 5.1\% of men agreed or strongly agreed that they regretted the biopsy.

Conclusions: Level of regret was low overall. Health anxiety was the only significant predictor of regret, with men with higher anxiety reporting higher levels of regret than men with low anxiety $(\mathrm{OR}=3.04,95 \% \mathrm{Cl} 1.58,5.84)$. Men with high health anxiety may especially benefit from careful counselling before and after prostate biopsy.

Keywords: Prostate, Biopsy, Regret

\section{Background}

Prostate biopsy is an invasive test that involves rectal insertion of an ultrasound probe to diagnose cancer of the prostate. It is usually prompted by a raised Prostate Specific Antigen (PSA), prostatic symptoms, an abnormal digital rectal examination (DRE) or a combination of these. The incidence of prostate cancer has until recently increased in most developed countries [1] and has the potential to increase further in future decades [2]. While acknowledging that predictions can be uncertain and that the ongoing debate about the benefits of screening for prostate cancer may also affect incidence, given population growth and the growing proportion of older people in the population, it is possible that the absolute number of biopsies will increase further. Prostate biopsy

\footnotetext{
* Correspondence: catherine.coyle@hscni.net

${ }^{\dagger}$ Equal contributors

${ }^{1}$ Public Health Agency, Belfast, Northern Ireland

Full list of author information is available at the end of the article
}

can be difficult for men to tolerate, and commonly results in physical side effects [3, 4] including bleeding, pain, urinary retention and infection. While the physical side effects have been well investigated, the psychological impact of prostate biopsy has been somewhat neglected $[5,6]$.

Decision-related regret is a negative emotion associated with thinking about a choice one has made or is about to make [7]. Evidence has grown which shows that men who choose different treatment options for prostate cancer report differing levels of regret, and the factors which predict regret have become a focus of investigation [8]. Previous studies of men with prostate cancer suggest that the demographic factors of: older age [8], being single [8-10] and lower educational attainment $[10,11]$ were associated with higher levels of treatment regret. Clinically, those experiencing treatment-related complications/side effects [8], with better pre-operative 
erectile function, post-operative incontinence, longer time from surgery to survey [8], and trait anxiety [9], were associated with higher levels of treatment regret. Decisional regret with respect to prostate biopsy does not appear to have been investigated.

The aim of this study was to investigate, for the first time, levels of decisional regret in men undergoing prostate biopsy and the factors associated with this. The hypothesis was that regret would be low and would not represent a significant burden for men undergoing prostate biopsy. The rationale for this was that men are likely to feel reassurance irrespective of the biopsy result; a negative biopsy result provides relief, and a positive result justifies the decision to proceed with biopsy.

\section{Methods}

\section{Setting}

The study took place on the island of Ireland, which comprises the Republic of Ireland (RoI) and Northern Ireland (NI). Four of the eight rapid access clinics (RAC) in the RoI public healthcare system agreed to take part in the study. In NI, two of the five Health and Social Care Trusts which are part of the public-funded NHS participated.

Ethical approval for the study was obtained for the four participating RoI hospitals and from the office for Research Ethics in Northern Ireland.

\section{Recruitment}

Men were recruited between November 2012 and December 2013. They were eligible to participate if they were undergoing prostatic biopsy as a result of a raised PSA level and/or an abnormal DRE, were over eighteen years of age, could understand English, were usually resident in either the RoI or NI, and were deemed well enough by their medical teams to complete a questionnaire, and in particular, had no cognitive impairment. They were ineligible if they had a previous diagnosis of prostate cancer.

Two methods of recruitment were used due to differing ethical and data protection requirements in the participating hospitals. In two hospitals in the RoI, a study information leaflet was sent to all men with their prostate biopsy appointment. Between four and six weeks post-biopsy these men were sent a questionnaire pack, with two reminder letters sent to non-responders at fortnightly intervals.

In the remaining hospitals all men, when attending for their prostate biopsy result, were given a questionnaire pack by nurse specialists. These men received no written reminders. In total 811 men were given/sent a questionnaire.

\section{Questionnaire}

The questionnaire captured socio-demographic information including date of birth, marital status, and educational attainment.
Men were asked about their urinary symptoms prior to first PSA test, and also questions about their route to PSA testing. They were also asked if, prior to biopsy, they had experienced urinary symptoms or erectile dysfunction. Information was requested regarding preparation for biopsy and number of cores taken.

Eighteen statements about men's feelings about prostate biopsy (both positive and negative) were developed based on discussions with prostate cancer survivor groups. Men were asked to record their level of agreement, on a 4-point Likert scale ranging from "strongly agree" to "strongly disagree", with each of the statements. Regret was measured with the statement "It [the biopsy] is something I regret."

Information was sought on the biopsy result. Men were asked questions about their experience of specific physical side effects following their most recent biopsy (fever, bleeding, pain, erectile dysfunction and urinary retention). Questions enquired about the severity, duration and need for treatment where these occurred.

The questionnaire was pretested with 24 men attending three prostate cancer groups in the RoI, and modified accordingly.

A copy of the questionnaire is included as Additional file 1.

\section{Statistical analysis}

As there is limited literature on regret of biopsy, the factors investigated were chosen based on the literature on regret after cancer treatment decisions, and are largely explorative. These included socio-demographic variables, health anxiety, clinical variables and physical side effects.

Ordinal logistic regression was used to explore relationships between these variables and regret. An initial univariate analysis was conducted. Physical side effects (fever, bleeding, pain, erectile dysfunction and urinary retention) were analysed as both 'any side effect', and also individually for an association with regret. Variables significant at $p<0.10$ were added simultaneously to a multivariate model and likelihood ratio tests obtained to assess whether each variable should be included in the final model $(p \leq 0.05)$. The proportional odds assumption was checked using a likelihood ratio test.

Chi-squared tests were used to investigate differences in characteristics between those who responded to the question on regret and those who did not.

Statistical analyses were conducted using STATA release 11 (StataCorp, College Station, TX).

\section{Results}

Three hundred thirty-five men responded to the survey (response rate $41 \%$ ). The demographic features of respondents are shown in Table 1 . The mean age was 63 years. Three-quarters of respondents $(76 \%)$ were married or co-habiting, and $75 \%$ finished education at 
Table 1 Socio-demographic and clinical characteristics of participants

\begin{tabular}{|c|c|}
\hline & $\begin{array}{l}\text { Frequency } \\
n(\%)\end{array}$ \\
\hline Total & $335(100.0)$ \\
\hline \multicolumn{2}{|l|}{ Socio-demographic variables } \\
\hline \multicolumn{2}{|l|}{ Age at questionnaire completion } \\
\hline$<65$ years & $192(57.3)$ \\
\hline$\geq 65$ years & $140(41.8)$ \\
\hline Missing & $3(0.9)$ \\
\hline \multicolumn{2}{|l|}{ Marital status } \\
\hline Married/partnership & $254(75.8)$ \\
\hline Other & $80(23.9)$ \\
\hline Missing & $1(0.3)$ \\
\hline \multicolumn{2}{|c|}{ Highest education level completed } \\
\hline Primary/ secondary school & $250(74.6)$ \\
\hline Third level & $78(23.3)$ \\
\hline Missing & $7(2.1)$ \\
\hline \multicolumn{2}{|l|}{ Employment status } \\
\hline Working & $128(38.4)$ \\
\hline Retired & $130(38.8)$ \\
\hline Other & 66 (19.7) \\
\hline Missing & $11(3.3)$ \\
\hline \multicolumn{2}{|l|}{ Health anxiety } \\
\hline Low & $112(33.4)$ \\
\hline Intermediate & $148(44.2)$ \\
\hline High & $74(22.1)$ \\
\hline Missing & $1(0.3)$ \\
\hline \multicolumn{2}{|l|}{ Clinical variables } \\
\hline \multicolumn{2}{|l|}{ Given choice of first PSA } \\
\hline Yes & $243(72.5)$ \\
\hline No & $63(18.8)$ \\
\hline Missing & $29(8.7)$ \\
\hline \multicolumn{2}{|l|}{ Pre-biopsy symptoms } \\
\hline \multicolumn{2}{|l|}{ Incontinence } \\
\hline None/mild & $244(72.8)$ \\
\hline Moderate/severe & $53(15.8)$ \\
\hline Missing & $38(11.3)$ \\
\hline \multicolumn{2}{|l|}{ Erectile dysfunction } \\
\hline None/mild & $239(71.3)$ \\
\hline Moderate/severe & $75(22.4)$ \\
\hline Missing & $21(6.3)$ \\
\hline \multicolumn{2}{|l|}{ Symptoms at time of PSA test } \\
\hline Asymptomatic & $188(56.1)$ \\
\hline Symptomatic & 119 (35.5) \\
\hline Other/Missing & $28(8.4)$ \\
\hline
\end{tabular}

Table 1 Socio-demographic and clinical characteristics of participants (Continued)

\begin{tabular}{ll}
\hline Enough information pre-biopsy & $270(80.6)$ \\
Yes received enough & $25(7.5)$ \\
Yes but would have liked more & $6(1.8)$ \\
No but did not want/need any & $13(3.9)$ \\
No but would have liked some & $21(6.3)$ \\
Missing & \\
Biopsy result & $109(32.5)$ \\
Negative & $118(35.2)$ \\
Positive & $108(32.2)$ \\
Don't know & \\
Expectations of side-effects & $117(34.9)$ \\
Same as expected & $46(13.7)$ \\
Worse than expected & $62(18.5)$ \\
Not as bad as expected & $97(29.0)$ \\
Did not have side-effects & $13(3.9)$ \\
Missing & $295(88.1)$ \\
Number of previous biopsies (including most recent biopsy) \\
One \\
More than one \\
Missing \\
Any side-effectz ${ }^{a}$ \\
Yes & $234(69.9)$ \\
Missing & $18(24.8)$ \\
\hline
\end{tabular}

${ }^{\mathrm{a}} \mathrm{Fever}$, bleeding, pain, erectile dysfunction and urinary retention

primary or secondary school level. 38\% were working and $39 \%$ retired at the time of survey completion. For just over two thirds (70\%) of men, their recent biopsy represented their first ever biopsy. Approximately one third of men reported a diagnosis of cancer, one third a negative biopsy result, and the remaining third did not know their result. $88 \%$ of men reported experiencing one or more physical side effects, most commonly bleeding (reported by $80 \%)$. Just over half (53.4\%) of respondents reported that these were the same or better than expected. Two thirds of men reported high or intermediate health anxiety.

Of the 335 men, $11.9 \%$ did not respond to the question on regret and thus were excluded from further analysis. More of the men who completed the regret question were married or in a partnership $(77.9 \%$ vs $62.5 \%, p=0.03)$ and had third level education $(26.7 \%$ vs. $2.5 \%, p=0.01$ ) compared to those who did not.

Of the 295 men who answered the regret question, $5.1 \%$ agreed $(1.4 \%)$ or strongly agreed $(3.7 \%)$ with the 
statement "It [the biopsy] is something I regret". 37.6\% of men disagreed, and $57.3 \%$ strongly disagreed.

The univariate analysis found significant associations between health anxiety $(p<0.01)$ and number of previous prostate biopsies (including the most recent biopsy) $(p=0.03)$ with regret (Table 2). There was no association with individual physical side effects and regret, or with 'any physical side effect'. In multivariate analyses, the significant association between increasing health anxiety and biopsy regret remained after adjusting for number of biopsies. After adjusting for health anxiety, the number of biopsies was no longer significantly associated with regret (Table 3).

\section{Discussion}

This study found that overall levels of regret were low (5\%) among men following prostate biopsy. A higher level of regret following prostate cancer treatment decisions (11-12\%) has been reported in a number of published studies $[8,10,12]$ suggesting the possibility of differences in how men view the decisions around biopsy and treatment. Further suggestion of the difference between biopsy and treatment regret is reflected in the different predictor variables significantly associated with regret in this study compared with the existing literature on regret following prostate cancer treatment. One theory to explain this difference and supported by our results is that these men may have received better pre-procedure counselling for prostate biopsy. This is based on more than $80 \%$ of men reporting that they received enough information before the biopsy, and less than one fifth of men had side effects worse than expected. Also, at this point more than one-third of these men did not have cancer, a fact for which they may be grateful that they had the biopsy. Further research is needed to clarify if and how predictors of regret in biopsy and treatment differ with the aim of ensuring men are appropriately prepared and counselled at each point in the prostate cancer diagnosis and treatment pathway.

The evidence base for PSA testing as a screening tool for prostate cancer - the route by which many men are referred for a prostate biopsy - includes conflicting results which has not as yet made a clear case for widespread PSA testing. However its use in Ireland [13] and elsewhere is widespread. Ransohoff and McNaughton Collins argue that this widespread use is because the system acts to make PSA attractive through positive feedback mechanisms [14]. A patient will be grateful for a negative PSA result or suspicious result followed by a negative biopsy; furthermore a positive PSA result followed by a cancer diagnosis makes the patient grateful for early detection. The clinician is also affected by positive feedback resulting from PSA testing and subsequent biopsy; we have previously shown that GPs who detect an asymptomatic prostate cancer via PSA testing were 3-times more likely to PSA test other asymptomatic men [15]. Additionally, litigation will usually only follow a cancer detected too late, not the one detected too early or which would never have caused harm.

This theory may explain why the level of regret reported by respondents in this survey was generally low; a negative biopsy result provides reassurance, and a positive result provides positive feedback that the test was worth it as the cancer has been detected.

Health anxiety was the only variable significantly associated with regret. Health anxiety can be thought of as a continuum, with hypochondriasis at the extreme. It is characterised by attentional biases towards illness-related information and cognitive biases leading to the misinterpretation of information as personally threatening and catastrophic [16]. Miles et al. [16] examined health anxiety in the context of screening for colorectal cancer and found that people with high health anxiety were less reassured following screening. In this study we found that men with higher health anxiety report higher levels of regret and, following from Miles et al. [16], it may be that men with high health anxiety were less reassured following prostate biopsy, and therefore were more likely to regret the procedure.

This study does have some limitations. The questionnaire designed to collect this data was in effect a new instrument. However it was tested for face validity and comprehension with 24 men in the RoI, and available validated tools were used within the questionnaire such as the Health Anxiety Questionnaire by Lucock and Morley, 1996. The limited sample size coupled with the low level of regret may explain in part why so few variables were associated with regret. The response rate is another limitation and we do not have any information on the characteristics of responders and non-responders, so we cannot assess participation bias. Respondents who answered the question on regret were more likely to be married or in a partnership and to have third level education than those who did not. The literature cited previously on regret after treatment decisions indicates that being married or in a partnership, and higher levels of educational attainment are associated with lower levels of regret. This suggests we may have somewhat underestimated regret in the current study.

The major strength of the study is that we were able to test a wide variety of variables for an association with regret. The inclusion of men from two jurisdictions with differing health systems increases generalizability.

The study overall can be viewed as a pilot study into regret among men following prostate biopsy and associated factors. This should raise the profile of this issue among researchers and the health community which may in turn lead to further research to explore this in other populations. 
Table 2 Results of univariate ordinal logistic regression testing for association of predictor variables with regret post-biopsy: odds ratios (OR) with 95\% confidence intervals $(\mathrm{Cl})$ and $p$-values

\begin{tabular}{|c|c|c|c|}
\hline & \multirow{2}{*}{$\begin{array}{l}\text { Frequency } \\
\text { n (\%) }\end{array}$} & \multicolumn{2}{|c|}{ Univariate Analysis } \\
\hline & & $\mathrm{OR}(95 \% \mathrm{Cl})^{\mathrm{a}}$ & $p$-value* \\
\hline Total & 295 (100.0) & & \\
\hline
\end{tabular}

Socio-demographic variables

Age at questionnaire completion

$\begin{array}{llll}<65 \text { years } & 174(59.0) & 1.00 & \\ \geq 65 \text { years } & 118(40.0) & 0.89(0.56,1.42) & 0.64 \\ \text { Missing } & 3(1.0) & & \end{array}$

Marital status

Married/ partnership

Other

229 (77..6) $\quad 1.00$

Missing

$65(22.0) \quad 0.99(0.57,1.71) \quad 0.96$

$1(0.3)$

Highest education level completed

$\begin{array}{llll}\text { Primary/secondary school } & 211(71.5) & 1.00 & \\ \text { Third level } & 77(26.1) & 0.67(0.40,1.14) & 0.14 \\ \text { Missing } & 7(2.4) & & \end{array}$

Employment status

$\begin{array}{llll}\text { Working } & 114(38.6) & 1.00 & \\ \text { Retired } & 117(39.7) & 0.72(0.43,1.22) & \\ \text { Other } & 55(18.6) & 1.17(0.62,2.19) & 0.27 \\ \text { Missing } & 9(3.1) & & \end{array}$

Health anxiety

$\begin{array}{llll}\text { Low } & 100(33.9) & 1.00 & \\ \text { Intermediate } & 132(44.8) & 1.80(1.05,3.10) & \\ \text { High } & 63(21.4) & 3.18(1.68,6.02) & 0.001 \\ \text { Missing } & 0(0.0) & & \\ \text { Clinical variables } & & & \\ \text { Given choice of first PSA } & & & \\ \text { Yes } & 215(72.9) & 1.00 & \\ \text { No } & 57(19.3) & 0.86(0.48,1.53) & 0.60 \\ \text { Missing } & 23(7.8) & & \\ \text { Pre-biopsy sympoms } & & & \end{array}$

Pre-biopsy symptoms

Incontinence

None/mild

Moderate/severe

Missing

Erectile dysfunction

$\begin{array}{llll}\text { None/mild } & 213(72.2) & 1.00 & \\ \text { Moderate/ severe } & 65(22.0) & 1.08(0.62,1.89) & 0.77 \\ \text { Missing } & 17(5.8) & & \end{array}$

Symptoms at time of PSA test

$\begin{array}{llll}\text { Asymptomatic } & 166(56.3) & 1.00 & \\ \text { Symptomatic } & 106(35.9) & 1.34(0.83,2.17) & 0.23 \\ \text { Other/Missing } & 23(7.8) & & \end{array}$

Table 2 Results of univariate ordinal logistic regression testing for association of predictor variables with regret post-biopsy: odds ratios (OR) with 95\% confidence intervals $(\mathrm{Cl})$ and $p$-values (Continued)

\begin{tabular}{|c|c|c|c|}
\hline \multicolumn{4}{|l|}{ Enough information pre-biopsy } \\
\hline Yes received enough & $238(80.7)$ & 1.00 & \\
\hline $\begin{array}{l}\text { Yes but would have liked } \\
\text { more }\end{array}$ & $24(8.1)$ & $1.84(0.81,4.19)$ & \\
\hline $\begin{array}{l}\text { No but did not want/need } \\
\text { any }\end{array}$ & $5(1.7)$ & $2.84(0.47,17.27)$ & \\
\hline $\begin{array}{l}\text { No but would have liked } \\
\text { some }\end{array}$ & $12(4.1)$ & $1.10(0.34,3.54)$ & 0.36 \\
\hline Missing & $16(5.4)$ & & \\
\hline \multicolumn{4}{|l|}{ Biopsy result } \\
\hline Negative & $106(35.9)$ & 1.00 & \\
\hline Positive & $97(32.9)$ & $1.45(0.84,2.51)$ & \\
\hline Don't know & $92(31.2)$ & $1.34(0.76,2.35)$ & 0.38 \\
\hline \multicolumn{4}{|l|}{ Expectations of side-effects } \\
\hline Same as expected & $108(36 . .6)$ & 1.00 & \\
\hline Worse than expected & $41(13.9)$ & $1.97(0.98,3.96)$ & \\
\hline Not as bad as expected & $54(18.3)$ & $1.39(0.72,2.68)$ & \\
\hline Did not have side-effects & $83(28.1)$ & $1.08(0.60,1.93)$ & 0.24 \\
\hline Missing & $9(3.1)$ & & \\
\hline \multicolumn{4}{|l|}{ Number of biopsies } \\
\hline One & $209(70.9)$ & 1.00 & \\
\hline More than one & $72(24.4)$ & $0.62(0.36,1.07)$ & 0.08 \\
\hline Missing & $14(4.8)$ & & \\
\hline \multicolumn{4}{|l|}{ Physical Side-effects from biopsy } \\
\hline \multicolumn{4}{|l|}{ Any side-effect ${ }^{b}$} \\
\hline Yes & $263(89.2)$ & 1.00 & \\
\hline No & $32(10.9)$ & $0.88(0.42,1.84)$ & 0.74 \\
\hline Missing & $0(0.0)$ & & \\
\hline
\end{tabular}

Table 3 Results of multivariate ordinal logistic regression: multivariate model including predictor variables which had $p$-value $<0.10$ in univariate ordinal logistic regression - odds ratios (OR) with 95\% confidence intervals $(\mathrm{Cl})$ and $p$-values

\begin{tabular}{lcc}
\hline Variable & OR $(95 \% \mathrm{Cl})$ & $p$-values* \\
\hline Number of previous biopsies (including most recent biopsy) & 1.00 & 0.17 \\
One & $0.68(0.39,1.19)$ & \\
More than one & & \\
Health anxiety & 1.00 & $<0.01$ \\
Low & $1.87(1.07,3.26)$ & \\
Intermediate & $3.04(1.58,5.84)$ & \\
High
\end{tabular}

${ }^{*} p$-values obtained from the likelihood ratio test 


\section{Conclusions}

In conclusion, regret is low overall shortly after a prostate biopsy. Men with high health anxiety are more likely to report higher levels of regret. These men may especially benefit from careful counselling before and after biopsy. Given the potential for the number of biopsies being performed to increase and the limited evidencebase, further research on different aspects of men's views and experiences of biopsy would be of value.

\section{Additional file}

Additional file 1: The PiCTure Study - Prostate Investigations in Ireland. This is a pdf version of the questionnaire used in the Republic of Ireland. (PDF $1351 \mathrm{~kb}$ )

\section{Abbreviations}

DRE: Digital rectal examination; NI: Northern Ireland; PSA: Prostate specific antigen; RAC: Rapid access clinics; Rol: Republic of Ireland

\section{Acknowledgements \\ The authors thank the clinical teams; Mr Garrett Durkan, Mr David Galvin, Mr Gordan Smyth, Ms Sheila Keily, Ms Sara White, Ms Eimear Dunne, Moya Power and Ms Rosaleen Padin, who facilitated recruitment of men to this study. The authors thank Dr Heather Kinnear for work in the design and administration of the survey. \\ Funding \\ Prostate Cancer UK, the Health Research Board and the R\&D office of NI Public Health Agency funded the study. The NI Cancer Registry is funded by the NI Public Health Agency and the National Cancer Registry Ireland by the Department of Health. None of the funding bodies had a role in the design, data collection, analysis or interpretation of the data contained within this manuscript.}

\section{Availability of data and materials}

The data are not available at this time because the study team are currently working on other papers based on these. The questionnaire is provided as Additional file 1

\section{Authors' contributions}

AG and LS obtained the initial funding for the study, and AG, LS and FJD obtained additional funding for the study. AG, LS and FD contributed to study design and questionnaire development. FD undertook data collection. EM and LS provided statistical advice and EM and CC analysed the data. All authors contributed to the interpretation of the results and drafting the manuscript. All authors have approved the final manuscript.

\section{Competing interests}

LS held an unrestricted project grant, 2011-2012, from Sanofi-Aventis for research into patterns of treatment and survival for prostate cancer.

The remaining authors have no competing interests.

\section{Consent for publication}

Not applicable.

\section{Ethics approval and consent to participate}

Ethical approval for the study was obtained for the participating Rol hospitals:

Beaumont Hospital 19/1/12

Mater Misericordiae University Hospital 2/5/13

University Hospital Galway 4/1/12

University Hospital Limerick 11/10/12

Ethical approval was granted in August 2012 from the Office for Research Ethics in Northern Ireland (ORECNI) (Ref 12/NI/0106). Potential participants received a pack either by post or in person depending on their study area, which included a study information sheet, questionnaire and consent form.
Those who chose to take part in the study were requested to return, by post, a completed and signed consent form together with the completed questionnaire.

\section{Author details}

${ }^{1}$ Public Health Agency, Belfast, Northern Ireland. ${ }^{2}$ Northern Ireland Cancer Registry, Queen's University, Belfast, Northern Ireland. ${ }^{3}$ National Cancer Registry Ireland, Cork, Ireland. ${ }^{4}$ Department of Epidemiology and Public Health, University College Cork, Cork, Ireland. ${ }^{5}$ Institute of Health \& Society, Newcastle University, Newcastle, UK.

Received: 4 March 2016 Accepted: 22 December 2016

Published online: 26 January 2017

\section{References}

1. Wong MCS, Goggins WB, Wang HHX, Fung FDH, Leung C, Wong SYS, $\mathrm{Ng} C \mathrm{CF}$, Sung JJY. Global incidence and mortality for prostate cancer: Analysis of temporal patterns and trends in 36 countries. Eur Urol. 2016; 70:862-74.

2. Maddams J, Utley M, Møller H. Projections of cancer prevalence in the United Kingdom, 2010-2040. Br J Cancer. 2012;107:1195-202.

3. Nobrega de Jesus CM, Correa LA, Padovani CR. Complications and risk factors in transrectal ultrasound-guided prostate biopsies. Sao Paulo Med J. 2006;124(4):198-202

4. Jeon SS, Woo SH, Hyun JH, Choi HY, Chaie SE. Bisacodyl rectal preparation can decrease infectious complications of transrectal ultrasound-guided prostate biopsy. Urology. 2003;62:461-6.

5. De Sio M, D'armiento M, Di Lorenzo G, Damiano R, Perdona S, De Placido S, et al. The need to reduce patient discomfort during transrectal ultrasonography-guided prostate biopsy: what do we know? BJU Int. 2005; 96:977-83.

6. Wade J, Rosario DJ, Macefield RC, Avery KNL, Salter E, Goodwin ML, et al. Psychological Impact of Prostate Biopsy: Physical Symptoms, Anxiety, and Depression. J Clin Oncol. 2013;31(33):4235-41.

7. Connolly T, Reb J. Regret in cancer-related decisions. Health Psychol. 2005: 24 Suppl 4:29-34

8. Lavery HJ, Levinson AW, Hobbs AR, Sebrow D, Mohamed NE, Diefenbach $M A$, et al. Baseline functional status may predict decisional regret following robotic prostatectomy. J Urol. 2012;188:2213-8.

9. Berry DL, Wang Q, Halpenny B, Hong F. Decision preparation, satisfaction and regret in a multi-center sample of men with newly diagnosed localized prostate cancer. Patient Educ Couns. 2012;88:262-7.

10. Sidana A, Hernandez DJ, Feng Z, Partin AW, Trock BJ, Saha S, et al. Treatment decision-making for localized prostate cancer: what younger men choose and why. Prostate. 2012;72(1):58-64.

11. Hu JC, Kwan L, Saigal CS, Litwin MS. Regret in men treated for localized prostate cancer. J Urol. 2003;169:2279-83.

12. Morris BB, Farnan L, Song L, Addington EL, Chen RC, Nielsen ME, et al. Treatment decisional regret among men with prostate cancer: Racial differences and influential factors in the North Carolina Health Access and Prostate Cancer Treatment Project (HCaP-NC). Cancer. 2015;121(12): 2029-35

13. Drummond FJ, Barrett E, Burns R, O'Neill C, Sharp L. The number of tPSA tests continues to rise and variation in testing practices persists: a survey of laboratory services in Ireland 2008-2010. Ir J Med Sci. 2014;183(3):369-75.

14. Ransohoff DF, McNaughton Collins M, Fowler FJ. Why is prostate cancer screening so common when the evidence is so uncertain? A system without negative feedback. Am J Med. 2002;113:663-7.

15. Drummond FJ, Carsin AE, Sharp L, Comber H. Factors prompting PSA-testing of asymptomatic men in a country with no guidelines: a national survey of general practitioners. BMC Fam Pract. 2009. doi:10.1186/1471-2296-10-3.

16. Miles A, Wardle J. Adverse psychological outcomes in colorectal cancer screening: does health anxiety play a role? Behav Res Ther. 2006:44:1117-27. 